\title{
HISTORISCHE REPRESENTATIVITEIT
}

\author{
Frank R. Ankersmit
}

Historici bezien de theorie doorgaans met een zekere irritatie. Dat laat zich gegrijpen. De psycholoog die een groep met elkaar discussiërende mensen begint te psychoanalyseren, zal ook van die groep weinig sympathie en waardering mogen verwachten. Men zal de psycholoog als enigszins verontrustend ervaren en zijn constateringen als niet ter zake doende in het kader van de binnen de groep gevoerde discussie. Niemand houdt ervan om 'geobjectiveerd' te worden - en in de relatie tussen historici en theoretici is het niet anders. Wel is het merkwaardig dat de historicus zoveel eerder geneigd is om de theoreticus arrogantie te verwijten dan dat de natuurkundige dit de wetenschapsfilosoof doet: natuurkundigen bekommeren zich zelden om het doen en laten van wetenschapsfilosofen. De verklaring is wellicht dat de historicus en de theoreticus toch dichter bij elkaar staan dan de natuurkundige (of de beoefenaar van een ander exacte wetenschap) en de wetenschapsfilosoof. En omdat het verwijt van onbevoegde inmenging in andermans zaken steeds door historici en nooit door de theoretici geformuleerd wordt, moeten wij deze relatieve nabijheid van geschiedbeoefening en theorie vooral interpreteren als een indicatie van het in wezen theoretisch, filosofisch karakter van de geschiedbeoefening.

Het is nuttig hier nog een moment nader op in te gaan. We kunnen dan constateren dat de relatie tussen theorie en praktische geschiedbeoefening een merkwaardig paradoxaal karakter draagt. Het paradoxaal karakter van die relatie openbaart zich wanneer we ons afvragen of en in hoeverre de theorie van een eigen autonomie heeft ten opzichte van de geschiedbeoefening; juist de in de vorige alinea geconstateerde relatieve nabijheid van theorie en praktische geschiedbeoefening verleent aan deze vraagstelling een zekere urgentie. Velen, zowel historici als theoretici verwerpen die autonomie. Ontnuchterd door het échec van de positivistische geschiedfilosofie met haar krasse ultimata aan de geschiedbeoefening beogen veel geschiedfilosofen nu weinig meer dan wat men met een al wat ouderwets woord aan zou kunnen duiden als een 'rationele reconstructie' van de praktische geschiedbeoefening. Dat wil zeggen, men aanvaardt de bestaande geschiedbeoefening zoals die reilt en zeilt en men probeert vervolgens een zekere logica in de werkwijze van de historicus te ontwaren. Historici, van hun kant, zeiden of suggereerden dat 
het vertrekpunt voor de theoreticus nooit het standpunt van een andere theoreticus zijn mocht, maar altijd een aspect van de praktijk van de geschiedbeoefening. Sommigen gaan nog verder en vinden dat de theorie zich het beste zou kunnen beperken tot de historiografische recapitulatie van de geschiedkundige arbeid uit heden en verleden. Het zal evenwel duidelijk zijn dat een dergelijk van de geschiedbeoefening direct afhankelijke, niet-autonome theorie voor die geschiedbeoefening zelf betrekkelijk irrelevant is (1). De theorie is hier niet meer dan een knecht en een knecht die de meester zelfs heel goed missen kan. De paradox is derhalve dat een autonome theorie, een theorie die zich tot op zekere hoogte laat leiden door haar eigen geschiedenis en door haar eigen vraagstellingen, juist meer betekenis voor de praktische geschiedbeoefening dan een theorie die niets meer beoogt te zijn dan een theoretische extrapolatie van de bestaande geschiedkundige praktijk. En hebben we niet in het algemeen meer aan mensen die het op gezette tijden met ons oneens durven te zijn dan aan degenen voor wie ons gelijk altijd het vertrekpunt is?

Voorts, het kost niet veel moeite om in te zien dat in het dilemma van autonomie of niet voor de theorie, de autonomie het zal moeten winnen. De discussie daarover ligt immers zelf buiten het terrein van de geschiedbeoefening en het standpunt dat de autonomie van de theorie verwerpt, is daarom al in strijd met zijn eigen (theoretische) natuur. Een dergelijk standpunt, hoe dan ook verdedigd, kan sui generis nooit meer zijn dan een slechts tijdelijke pacificatie van de vruchtbare frictie tussen theorie en praktijk. Zoals de waarde van de theorie ligt in de discrepantie tussen theorie en praktijk, zo ligt ook de levensvoorwaarde van de theorie in diezelfde discrepantie. En dit heeft zijn gevolgen voor hoe we het geschiedtheoretisch debat moeten interpreteren en moeten lezen - althans voor wat betreft de vraag naar wat de belangrijkste stimulator is van de voortgang van het theoretisch debat. Conform bovenstaande these van de autonomie van de theorie moeten we die stimulator niet zoeken in het steeds weer constateren van vroeger vergeten of op de achtergrond gebleven eigenschappen van de praktische geschiedbeoefening, maar in de innerlijke logica die het theoretische debat voortstuwt. Erkenning van de autonomie van de theorie noopt ons tot een accentueren van de band tussen de verschillende theoretische standpunten ten koste van de band tussen theorie en praktijk. En, alweer, het paradoxale gegeven is dat de theorie ook eerst dan voor de praktische geschiedbeoefening van betekenis kan zijn.

Aanvaarden we de these van de autonomie van de theorie, dan is het mogelijk om drie fasen te onderscheiden in de evolutie van de theorie sinds 1945. Er is allereerst een fase waarin de geschiedbeoefening vooral onderzocht wordt vanuit het perspectief van beschrijving en verklaring, vervolgens zien we een fase waarin het draait om de interpretatie van het verleden en, tenslotte, tegenwoordig bevinden we ons in een fase waarin men zich de geschietbeoefening vooral denkt als 
een representatie van het verieden - de narrativistische standpunten die sinds White's Metahistory verdedigd worden, hebben de aandacht voor representatie als hun grootste gemene deler. Het is waar dat er tegenwoordig sprake is van een streven 'to go beyond representation' (2). Achtergrond van dit streven is dat het begrip 'representatie' een splitsing suggereert tussen wat representeent en het gerepresenteerde, een splitsing die men strijdig acht met het geconstrueerde karakter van zelfs het gepresenteerde. We hebben, om zo te zeggen, slechts de beschikking over representaties en als dat inderdaad het geval is, kan het woord representatie niet langer zinvol gebruikt worden. Maar of zich hier daadwerkelijk een vierde fase aankondigt, valt op dit moment nog niet te zeggen. Evenmin is het duidelijk hoe zo'n vierde fase er in concreto uit zou moeten zien.

Beperken we ons daarom tot de eerste drie fasen dan zouden we die ook aan kunnen duiden als primo de wetenschapsfilosofische securdo de hermeneutische en tertio de esthetische fasen van de geschiedtheorie. Immers, de wetenschapsfilosofie houdt zich bij voorkeur bezig met de vraag hoe men beschrijft en verklaart in de verschillende disciplines; de hermeneutiek, zoals beoefend door Droysen, Dilthey of Gadamer, wil ons tonen hoe wij teksten of het handelen van historische actors interpreteren. En de estheticus, tenslotte, onderzoekt de aard van de artistieke representatie van de wereld.

Men kan zich afvragen waardoor deze evolutie van een wetenschapsfilosofische, via een hermeneutische naar een esthetische geschiedtheorie gestimuleerd wordt. Vanzelfsprekend valt daar veel meer over te zeggen dan in dit verband zinvol is (3). Maar de belangrijkste factor lijkt mij hier wat men zou kunnen omschrijven als de toenemende problematisering van het historisch object - een problematisering die zijn voorlopig hoogtepunt vindt in het hierboven vermelde streven 'to go beyond representation'.

Bezien wij de drie verschillende fasen vanuit dit perspectief.

Wie spreekt over de beschrijving en de verklaring van het verleden, zoals dat in de eerste, wetenschapsfilosofische fase gedaan werd, suggereert daarmee de aanwezigheid van een betrekkelijk probleemloos gegeven historisch object dat tegenover ons ligt, evenals de objecten uit de fysische werkelijkheid, en dat vervolgens - voor wat betreft zijn eigenschappen - beschreven en verklaard kan worden. De hermeneuticus, met zijn aandacht voor de rol van de historicus als kennend subject, zal vervolgens al veel minder geneigd zijn het verleden als een van de historicus losstaand quasi-object te zien. Bij Gadamer leidt dat zelfs tot de gedachte dat het historisch object zich eerst constitueert in en door de confrontatie van de historicus met het verleden. Om het met een ruimtelijke metafoor uit te drukken, het verleden ligt hier in de opening tussen de historicus en de plaats waar de wetenschapsfilosofische theoreticus het historisch object zou willen situeren. (In het algemeen is het vaak nuttig om filosofische debatten te vertalen in termen van ruim- 
telijke metaforen, aangezien die metaforen vaak de eigenlijke inspirators zijn van het filosofisch debat; zoals Derrida suggereert, begrijpen we een filosofisch standpunt vaak eerst nadat we ons er een ruimtelijke voorstelling van hebben gemaakt. Trekken we de lijn door dan zien we in de esthetische representatie van het verleden de meest vergaande problematisering van het historisch object. We zijn immers geboeid door het kunstwerk juist omdat het meer is dan een mechanische, mimetische copie (ikoon) van wat het representeert; juist daardoor kan het kunstwerk ons ook tot een ander mens maken in de zin dat het ons leert de wereld met andere ogen te bezien. Verlangt de wetenschapsfilosofische fase de aanpassing van het subject aan het object, de hermeneutische van het object aan het subject, dan verschilt de esthetische representatie van beide, omdat hier de representatie (die in de beide andere gevallen slechts het medium is tussen subject en object) de cruciale factor is. Het kunstwerk heeft een eigen onafhankelijkheid: zowel van de kunstenaar als van wat het representeert. Om het wat pompeus te formuleren, het kunstwerk is zelf een oorsprong en niet een bemiddelende instantie tussen wereld, intenties van de kunstenaar en het publiek (4).

Ik beklemtoon dat, wat hier over de problematisering van het historisch object in de historische representatie gezegd wordt geenszins in idealistische zin geïnterpreteerd dient te worden. Die problematisering betekent niet dat de historicus de verleden werkelijkheid, het historisch object, zelfstandig scheppen zou. Dat zou een terugval betekenen van de esthetische fase naar die van beschrijving en verklaring - het oude dilemma van idealisme versus realisme is een dilemma dat alleen binnen de 'Weltanschauung' van de wetenschapsfilosofische fase zijn zin en betekenis heeft. Inderdaad, wenst men conform die 'Weltanschauung' het verleden te zien als een aggregaat van historische objecten, dan ligt de beschuldiging van idealisme voor de hand en is zij zelfs terecht; binnen de esthetische representatie is het dilemma tussen het (idealistisch) scheppen van de wereld en het (realistisch) ondergaan van, of zich onderwerpen aan die wereld onzinnig. Het feit dat men bijvoorbeeld de schilderijen, die Cézanne van de omgeving van Aix-en-Provence maakte, even goed als een idealistische abstractie van de wereld als een realistische benadering daarvan karakteriseren kan, bewijst dat de begrippen realisme en idealisme niet met de artistieke representatie in verband gebracht moeten worden. In én woord, de artistieke representatie is noch idealistisch, noch realistisch, omdat het kunstwerk geen medium is; noch tussen subject en object, noch tussen kunstenaar en publiek. We zien naar en niet door het kunstwerk. Ongetwijfeld is de muziek het nec plus ultra van deze aan de artistieke representatie inherente tendentie. Wat aanvankelijk (in de sfeer van beschrijving en van interpretatie) slechts een medium was, wordt in de representatie een (zelfstandig) object. Aldus bewerkt de artistieke representatie een vervreemding van de objecten van de wereld. En er moet op gewezen worden dat de esthetica als theorie van de artistieke representatie die 
vervreemding van de objecten van de wereld zelfs verlangt voor de objecten uit de alledagelijkse wereld waar die in de beeldende kunst afgebeeld worden. Dat wil zeggen: voor objecten waarvan wij geen moment betwijfelen dat zij een van de representatie onafhankelijk bestaan leiden. Wat daarom plausibel en verdedigbaar blijkt te zijn voor de artistieke representatie van de wereld in de beeldende kunst, is nog des te plausibeler voor de 'esthetische' representatie van het verleden en van het historisch object: het geconstrueerd karakter van het verleden en van wat het verleden bevatten zou, is evidenter nog dan dat van de in het kunstwerk gepresenteerde werkelijkheid. Vanuit dit perspectief zou men eerder nog van het 'historisch' karakter van de artistieke representatie kunnen spreken dan van het 'esthetisch' karakter van de historische representatie.

Hierboven wordt verdedigd dat juist cen autonome theorie niet indifferent zal zijn ten aanzien van de praktijk van de geschiedbeoefening. We kunnen ons daarom nu afvragen welke verschuiving in de historiografische praxis met de geschetste evolutie in de theorie van beschrijving via hermeneutiek naar representatie correspondeert. Dat brengt mij bij de kem van mijn betoog: welk doel stelt men zich in een geschiedschrijving die zich concentreert op beschrijving en interpretatie, en welk ander doel binnen een geschiedschrijving waar het historisch object geproblematiseerd is? Ik wil de hier bedoelde evolutie karakteriseren als cen evolutie van een 'fetishistische' naar een 'genealogische' geschiedschrijving. Beide termen zal ik hieronder nader toelichten. In deze fase van mijn betoog volsta ik met de toelichting dat de fetishistische geschiedbeoefening streeft naar de coagulatie en concentratie van complexe samenhangen of eenheden rond cen thema of begrip dat als een fetish functioneert, terwijl de genealogische geschiedbeoefening een dispersief karakter heeft en een dergelijke coagulatie rond een thematisch centrum juist ongedaan wenst te maken. De genealogische geschiedschrijving wil zo cen dispersie van het verleden bewerken door de eenheid van het verleden op te lossen in de afzonderlijke elementen waaruit die eenheid aanvankelijk was opgebouwd. Concreter, het gaat hier om de evolutie van Ranke naar Ginzburg en zijn 'microstorie'. De 'micro-storie' - waarin kleine en ogenschijnlijk onbetekenende voorvallen worden behandeld - bereiken het zojuist bedoelde dispersieve effect door het verband van het in de 'micro-storie' verhaalde met de tijd waarin zij zich afspelen af te zwakken. De 'micro-storie' verkrijgen daarmee tot op zekere hoogte een boven- of transhistorisch karakter. De overgang van Ranke naar Ginzburg is daarom de overgang van een modernistisch verlangen om het verleden, in de meest letterlijke zin van het woord, 'in de greep' te krijgen, om een handvat te construeren met behulp waarvan het verleden conceptueel georganiseerd kan worden, naar een post-moderne eliminatie van alle spanning in de relatie tussen heden en verleden. Voor de modernist - en het maakt daarbij weinig verschil of hij Ranke of Braudel heet - ligt in het op het algemene of op eenheid gerichte karakter van zijn ge- 
schiedkundig inzicht het bewijs dat hij tot het wezen van het verleden is doorgedrongen; de post-modernist is er zich van bewust hoezeer het geloof, dat met een dergelijk inzicht een historische realiteit correspondeert, een illusie is. Alweer, niet omdat de post-modernist een scepticus of een idealist is, maar omdat de post-modernist zich bewust is van het esthetisch karakter van het historisch inzicht: het historisch inzicht is geen medium, maar een object.

Het in oorsprong anthropologische begrip 'fetish' heeft veel van zijn tegenwoordige populariteit te danken aan Freuds gebruik daarvan. Eigenlijk is dat vreemd, omdat Freud het begrip, anders dan men vaak denkt, maar weinig gebruikt en er pas laat, in 1927, een overigens relatief kort artikel aan wijdt (5). Bovendien bindt Freud het begrip sterk aan een bepaalde psychopathologie. Een bredere betekenis verkrijgt het begrip, onder meer, in het werk van de Franse psychoanalyticus Jacques Lacan. Malcolm Bowie omschrijft de rol van de fetish bij Lacan als volgt: "het onbewuste verlangen, onverwoestbaar en onverzadigbaar, veroorzaakt een continue verplaatsing van energie van object naar object en is derhalve metonymisch. Een tot stilstand komen van de metonymische functie veroorzaakt niet een symptoom maar een fetish" (6). De gedachte hierbij is de volgende. De fetish functioneert als een fixatiepunt waar de metonymische betekenis-proliferatie van het freudiaanse 'Verschiebungs'-mechanisme onverwachts tot stilstand komt en waar daardoor zich een overmaat van associaties en betekenissen aan vast kunnen hechten. Bijgevolg kan de fetish een object zijn dat een rijkdom aan betekenissen heeft die ver boven het intrinsieke belang ervan uitgaat. De fetish kàn als zo'n fixatiepunt functioneren, omdat (en zolang) hij louter een gezichtspunt is van waaruit bepaalde delen van de wereld georganiseerd worden zonder dat dat gezichtspunt bewust gemaakt wordt. De fetish kan eerst een dergelijke betekeniswinst voor zichzelf realiseren door zich van zichzelf geen rekenschap af te leggen. Hij blijft voor zichzelf een 'dood' punt, een leegte; hij herkent niet wat men de 'binnenkant' van de fetish zou kunnen noemen. Een in het kader van dit betoog nuttig voorbeeld is die eigenaardige psychische duizeling die we allen soms ervaren wanneer we over een bepaald woord of een eigennaam (vooral die van onszelf) gaan nadenken alsof we dat woord of die eigennaam voor het eerst horen. Het blijkt dan dat die woorden en eigennamen een onvermoede 'binnenkant' bezitten waarvan we ons in de alledagelijkse omgang ermee zelden of nooit bewust zijn. Slechts in bepaalde versprekingen en onverwachte associaties worden we aan die 'binnenkant' herinnerd (7).

Tegen deze achtergrond zal het fetishistisch karakter van de historiografische traditie van Ranke evident zijn. Het tegenwoordig historisch besef, of dat nu zijn uitdrukking vindt in een historische, dan wel in een sociaal-wetenschappelijke geschiedschrijving, de wijze waarop wij ons gewoonlijk rekenschap geven van het verleden, wordt allereerst bepaald door bepaalde historische theses, die hun uit- 
drukking vinden in hoe wij het verleden periodiseren en vervolgens in de belangrijkste historische begrippen (als 'de Verlichting' of 'de Industriele Revolutie') in termen waarvan wij onze relatie tot het verleden plegen de definiëren. Het fetishistisch karakter van dergelijke begrippen spreekt voor zichzelf. Dergelijke begrippen zijn de perspectieven van waaruit wij het verleden organiseren. Evenals de fetish dienen zij als aanhechtingspunten voor wat wij over het verleden willen beweren. Men zou ze kunnnen vergelijken met de zogenaamde 'zwarte gaten' uit de astronomie die ook allerlei materiaal absorberen zonder ooit zelf zichtbaar te worden (8). We bezien het verleden en onze eigen plaats ten opzichte van het verleden vanuit het perspectief van de interpretatie van het verleden zoals die sinds het begin van de vorige eeuw ontwikkeld worden, maar, zoals dat met de fetish het geval is, zonder ons van die 'binnenkant' van de fetish bewust te zijn. Sterker nog, we kunnen ons geen voorstelling maken van wat die 'binnenkant' zou zijn en hoe we voor het openbreken van de historische fetish te werk zouden moeten gaan.

Dat laatste leert ons nu de genealogie. De genealogie van Nietzsche en Foucault kan men het beste zien als een omkering of een binnenste buiten keren van de fetishistische, historistische geschiedbeschouwing - en in dit gegeven ligt ook de sleutel van de deur die toegang geeft tot de 'binnenkant' van de fetish. De blik is hier niet gericht op genese, wording, samenhang, eenheid of continuiteit; de geneologie wil het bedriegelijke van de door dergelijke noties geïnspireerde patronen aan de kaak stellen. Genealogie is een lezen van het verleden in omgekeerde richting; de door het fetishistisch historisme afgelegde weg wordt in omgekeerde richting opnieuw afgelegd, en het resultaat is dat de orde van de fetish verruild wordt voor een oorspronkelijke wanorde. In dit lezen van de geschiedenis tegen de draad in, in dit ongedaan maken of in deze 'deconstructie' van het geaccepteerde beeld van het verleden, openbaart zich de 'binnnenkant van de fetish. Ik citeer Foucault: "de genealogie heeft niet de pretentie terug te gaan in de tijd om een ongebroken continuitteit te herstellen waarvan de werking uitgaat boven de dispersie of verspreiding van vergeten dingen; haar plicht is niet het voortbestaan van het verleden in het heden aan te tonen door een vooraf bepaald schema aan de wisselvalligheden van de geschiedenis op te leggen. Genealogie lijkt niet op de evolutie van een soort, noch brengt zij het lot van een volk in kaart, integendeel. Het volgen van het pad waarlangs men in het verleden afdaalt, verlangt dat wij de gebeurtenissen in hun spreiding bewaren; dit is een.identificatie van toevalligheden, minitieuze afwijkingen - of, anders, complete koersveranderingen - van de fouten, de onjuiste inschattingen, en van de onjuiste calculaties die aanzijn geven aan de dingen die bestaan en waarde voor ons hebben; het is een ontdekken dat waarheid en zijn niet aan de wortel liggen van wat we weten en van wat we zijn, maar in de aan dat alles externe toevalligheden". (9). Het historisme wil een melodie horen in het geluid van het verleden; de genealogie hoort slechts de ruis, de statica ervan. 
Beluisteren we wat Foucault zegt over de genealogie, dan valt op hoezeer hij die in verband brengt met 'verspreiding van vergeten dingen', met 'toevalligheden', 'minitieuze afwijkingen', 'koersveranderingen' of 'fouten', kortom met de stijl en de inhoud van zijn eigen boek over Pierre Rivière of van Ginzburgs 'microstorie'. De alomvattende structuren, patronen, verbanden en meta-narratieven waarmee het fetishistisch historisme het verleden poogde te organiseren, desintegreren in de denkwereld van de genealogie. Maar wel moeten we daarbij steeds bedenken dat de genealogie dit effect bewerken kan, niet door een geheel nieuwe richting in te slaan, alswel door een wending van honderdtachtig graden ten opzichte van de tot dusver gevolgde route. De genealogie is een ont-domestisering van het verleden, om met Hayden White te spreken (10), en veronderstelt daarom een domestiseringsproces dat eraan voorafgaat. Vandaar ook de onvermijdelijke afhankelijkheid van de genealogie van de fetish van het historisme en, vervolgens, het in wezen kritisch karakter van de genealogie. Ontegenzeggelijk heeft de genealogie iets parasitairs. Hoe dan ook, het resultaat van de arbeid van de genealogie is dat de onderdelen van het verleden in cen ongebonden staat naast elkaar komen te staan: genealogie "fragmenteert wat als eenheid was gedacht; zij toont de heterogeniteit van wat als consistent met zichzelf was verbeeld" (11). De 'micro-storie' zijn het logisch gevolg van de genealogische deconstructie van de fetish van het historisme.

Zoals bekend, kenden Nietzsche en Foucault aan de geneologie een therapeutische taak toe. Het inzicht in de aard en de genese van de historistische fetish betekent de bevrijding van een maatschappelijke neurose of dwangvoorstelling. Hier zijn Nietzsche en Foucault veel meer de erfgenamen van de Verlichting dan zij zichzelf graag presenteren, en hier kan men daarom ook vraagtekens plaatsen bij Charles Taylors bewering dat het verontrustende van Foucault zou liggen in zijn stelling dat kennis niet, zoals de Verlichting dacht, tot bevrijding leiden zal (12). Zeker is het zo dat de genealogie eerder het ongedaan maken van pseudowaarheden betreft, dan het ontdekken van nieuwe waarheden. Maar zou men niet kunnen opwerpen dat er steeds cen waarheid achter de ontmaskerde pseudo-waarheid verscholen gaat?

Het vervolgen van dit thema, hoe interessant ook, zou ons wegvoeren van de problematiek van de historische representativiteit en van de 'micro-storie'. Ter afsluiting van mijn betoog wil ik mij concentreren op de vraag hoe de 'micro-storie', ondanks hun door de genealogie geïnspireerde afwijzing van de integratieve, historistische geschiedbeoefening, toch geacht kunnen worden het verleden te representeren. Of, anders geformuleerd, op de vraag in wat voor opzicht de genealogische 'micro-storie' representatief kunnen zijn voor meer dan wat in de 'micro-storie' zelf verhaald wordt. Juist een geschiedschrijving en een theorie die een representatie van het verleden beoogt, wordt - het spreekt vanzelf - met deze vragen ge- 
confronteerd. Twee antwoorden op onze vraag naar de aard van de historische representativiteit kunnen we terzijde leggen. Zouden we zeggen dat de op representatie gerichte geschiedschrijving, dat wil zeggen, de 'micro-storie' 'representatief' zijn in de zin dat zij het individuele geval betreffen dat ons in staat stelt te redeneren naar een algemene karakteristiek van een periode, of omdat zij in nuce de betekenis dragen van een historische periode, dan zouden we het begrip 'representativiteit' weer terugvoeren naar de vroegere fasen van de beschrijving en van de interpretatie van het verleden. Maar we moeten de genealogische 'micro-storie' niet zien als de individuele gevallen van een algemene regel (hier wordt representativiteit gemodelleerd op het 'covering law model' - volgens welke het individuele geval slechts geïdentificeerd, beschreven en verklaard kan worden dankzij deductie uit een algemene wetmatigheid) noch als de micro-kosmos behorend bij een omvattender historische macro-kosmos (de hermeneutische duiding van het begrip representativiteit). Onze vraag is daarom, wat voor nieuwe inhoud moeten we aan het woord 'representativiteit' toekennen opdat we van de 'micro-storie' kunnen zeggen dat zij het verleden representeren, dan wel dat zij representatief zijn voor het verleden?

Ik heb niet de pretentie een afdoende antwoord op deze vragen te kunnen bieden, maar meen toch in aansluiting bij Nelson Goodman een suggestie in die richting te kunnen doen. Ik denk daarbij met name aan zijn Languages of art; dit brengt ons daarom weer terug bij de esthetica en bij de vraag naar de aard van de esthetische representatie. Dit gegeven rechtvaardigt het vermoeden dat ook hier een esthetisch georienteerde geschiedfilosofie de meeste kans van slagen hebben zal.

Over de aard van de esthetische representatie van het kunstwerk zijn sinds de Oudheid drie theorieern in omloop: de esthetische representatie is een kwestie van 1) imitatie, 2) vormgeving en 3) van de uitdrukking van een gevol of bedoeling (13). Met betrekking tot deze laatste theorie beklemtoont Goodman dat dat gevoel of die intentie niet, of althans niet noodzakelijkerwijs, met de subjectieve gevoelens van de kunstenaar in verband gebracht moet worden, maar slechts met het kunstwerk als zodanig. Zo kan een schilderij droefheid uitdrukken, maar dat betreft dan slechts het schilderij en niet de kunstenaar. Bijgevolg kan datgene wat het kunstwerk uitdrukt ook heel iets anders zijn dan een gevoel of intentie van de schepper ervan. Juist daardoor is deze derde theorie een geschikte achtergrond voor een behandeling van de geschiedkundige representatie: welke opvatting we daarover ook zijn toegedaan, we zullen wat een geschiedschrijving 'uitdrukt' nooit met de historicus, maar toch op éen of andere manier steeds met het verleden associëren. Goodman kiest zijn uitgangspunt bij de derde theorie. Hij ontwerpt vervolgens een ingenieuze theorie over wat de aard is van de artistieke expressie. Kernbegrip in deze theorie is het begrip 'exemplificatie'. Hij licht dat begrip toe aan de hand van het volgende voorbeeld: "Denken we aan het stalenboekje van een kleermaker. De 
stalen functioneren als 'symbolen' die bepaalde eigenschappen als voorbeeld stellen. Maar de staal exemplificeert niet al de eigenschappen die hij heeft. Het is een staal voor kleur, weefsel of patroon, maar niet voor afmeting, vorm, soortelijk gewicht of voor waarde. En zelfs exemplificeert het niet alle eigenschappen die het gemeen heeft met de rol waar de staal van afkomstig is - zoals bijvoorbeeld het gereedgekomen zijn op dinsdag" (14). Onder weglating van enkele details die wel voor Goodman, maar hier niet van belang zijn, kan het fenomeen van de exemplificatie als volgt gedefinieerd worden: $a$ exemplificeert $b$ wanneer $a$ naar $b$ verwijst dankzij een door de context bepaalde reeks van eigenschappen die ons in staat stellen om van $a$ tot $b$ te besluiten.

Over de merites van Goodmans exemplicatie als theorie van de artistieke expressie zal ik mij hier niet uitlaten. Waar het mij om gaat is het licht dat met behulp van de exemplificatietheorie geworpen kan worden op de historische representatie en de representativiteit van de 'micro-storie'. Cruciaal zijn daarbij de volgende drie kenmerken van de exemplificatie. Ten eerste constateren we hier een soort van implosie van het totaal van eigenschappen van wat exemplificeert ten opzichte van wat geexxemplificeerd wordt. Want, zoals Goodman opmerkt, lang niet alle eigenschappen van de kleermakersstaal worden door de staal geexxemplificeerd. Hier verschilt de exemplificatie op een bevredigende manier van hoe de geschiedkundige representatie opgevat zou moeten worden vanuit het paradigma van beschrijving en verklaring en dat van de hermeneutiek. Ook aan het context-gebonden karakter van de exemplificatie kan een zinvolle duiding worden gegeven: het ligt voor de hand in de fetish de context te zoeken, die binnen de genealogische geschiedschrijving ongedaan gemaakt wordt. Zoals in het voorbeeld van de kleermakersstaal een zeer bepaalde context de exemplificatorische functie van de kleermakersstaal 'kanaliseert', zo wordt het hier gedaan door de historistische fetish. In de tweede plaats is exemplificatie eerder een kwestie van tonen dan van beschrijven. De staal is niet een beschrijving van waar het een staal van is; wat exemplificeert, toont zich evenzeer als datgene wat ermee getoond wordt (15). In de derde en meest belangrijke plaats loopt verwijzing hier in een richting tegengesteld aan wat wij van verwijzing gewend zijn. Normaal is het zo dat wij eigenschappen gebruiken om naar dingen te verwijzen, om dingen te identificeren. Zo kan men Gorbachev aanduiden met de beschrijving: 'de politieke leider van het meest uitgestrekte land van deze aarde'. In de exemplificatie daarentegen is de verhouding tussen dingen, hun eigenschappen en verwijzing het omgekeerde van wat gewoonlijk het geval is. "Exemplificatie en expressie verlopen in een richting omgekeerd aan die van denotatie" (16), aldus Goodman.

Het is een weinig stoutmoedig veronderstelling dat in termen van deze drie karakteristieken van de exemplificatie.de historische representativiteit van de 'micro-storie' verhelderd kan worden. Zij zijn representatief voor, zijn een symbool 
van, staan voor en verwijzen naar een groter deel van het verleden dan zijzelf - zij het, dat het hier, zoals we in de vorige alinea al constateerden, om een zeer specifieke vorm van verwijzing en van representativiteit gaat. De context, die deze exemplificatie beheerst, is die van de bestaande fetishistische historiografie; de betekenisdraden die door deze historiografie getrokken worden, zijn tevens het web waarlangs de exemplificatie van de 'micro-storie' zich voltrekt - zij het in omgekeerde richting. In zekere zin zijn de 'micro-storie' de 'negatieve' geschiedenis van de geaccepteerde historiografie. Een sterkere afhankelijkheid van een reeds bestaande historiografische context dan hier, zal men nergens elders aan kunnen treffen. Er valt iets voor te zeggen de 'micro-storie' als een parodie op de geaccepteerde geschiedbeoefening te zien. Daarom, ondanks hun populariteit bij een breed publiek, zijn de 'micro-storie' in wezen 'historians's historiography' (17). In de tweede plaats toont het verleden zich in de 'micro-storie' eerder dan dat er sprake is van een beschrijving van het verleden. Er is hier een element van directheid en onmiddellijkheid die men elders minder aantreft - wel is dit een kwestie van nuance. En in de derde plaats - ook hier is dat weer het belangrijkste - loopt de verwijzing van detail naar geheel, in plaats van omgekeerd. Doorgaans is het detail een afgeleide of een illustratie van een groter geheel, maar hier is die verhouding omgekeerd. Het exemplificeert een deel een geheel, hoewel toch het zwaartepunt bij het detail kan blijven liggen (dat kan dankzij de alom aanwezige context van de gangbare historiografie). Anders dan bij het historisme dat zijn inspiratie vindt bij de fetish van de eenheid, van oorsprong en van totaliteit, blijft in de 'micro-storie' het detail de sterkere partij. Maar, zoals wij eerder de gelegenheid hadden te constateren, de overwinning van de 'micro-storie' is en blijft door hun in wezen parasitair karakter slechts een Pyrrhus-overwinning.

Ter afsluiting een korte recapitulatie. Neemt men de 'micro-storie' au séri$e u x$ dan belichamen zij een onverwachte uitdaging aan traditionele concepties. $\mathrm{Zij}$ ontwrichten namelijk de verhouding tussen het belangrijke en het onbelangrijke zoals wij die kennen uit de historiografische traditie. Niet een wetenschapsfilosofische, noch een hermeneutische, maar een esthetische geschiedfilosofie lijkt de beste kansen te hebben om ons inzicht in de aard van de 'micro-storie' te verdiepen. Het probleem waar zij ons voor plaatsen betreft immers niet een beschrijving of een interpretatie, maar de representatie van het verleden. En onze vraag is derhalve, wat voor inhoud moeten we aan het begrip 'representatie' toekennen, opdat we mogen zeggen dat de 'micro-storie' het verleden representeren. Het blijkt dat Goodmans theorie over exemplificatie hier het best van dienst kan zijn.

\section{Noten}

1) Zie het themanummer van Leidschrift, Leiden 1988 , Over nut en madeel van geschied- 
theorie voor de historicus; zeer aan te bevelen is ook W.J. van der Dussen, Filosofie van de geschiedenis, Muiderberg 1986; hfdstk. $1 \mathrm{t} / \mathrm{m} 4$.

2) Verschillende leden van de Poroi-groep, theoretici over de rol van de rhetorica in verschillende disciplines, denken in deze richting. De Poroi-groep is gevestigd aan de universiteit van Iowa.

3) Zie hiervoor mijn Historical representation dat binnenkort verschijnt in History and theory.

4) Zie voor de zeer wezenlijke betekenis van media als hier bedoeld mijn In search of the political object; Stoic and aesthetic political philosophy, dat volgend jaar verschijnen zal in een bundel van de New School for Social Research.

5) S. Freud, Fetischismus, in: id., Studienausgabe Bd. 3, Frankfurt am Main 1983, $397 \mathrm{ff}$.

6) M. Bowie, Jacques Lacam, in: J. Sturrock, Structuralism and since, Oxford 1984, 130.

7) In plaats van het 'fetishisme' van de historische traditie zou men hier ook kunnen spreken van het 'mythische' element van die traditie. Ik denk hier aan Barthes' kritiek op het historisme voor zover dit ertoe stimuleert om wat een historisch karakter heeft als iets quasi-natuurlijks en onontkoombaars te presenteren. Het woord 'mythe' suggereent echter 'onwaarheid', of zelfs bedrog, en die associatie wens ik.te vermijden. Het gaat hier niet om een kwestie van waarheid en onwaarheid, maar om het feit dat het innemen van een standpunt een merkwaardige blindheid voor dat standpunt zelf genereert; men beziet de wereld vanaf zijn standpunten, maar niet die standpunten zelf. Het neutralere woord 'fetish' verdient daarom de voorkeur en zelfs dat woord heeft voor velen een peioratieve klank die hier zeker niet op zijn plaats zou zijn. Inzake de polariteit van fetish en genealogie is er geen 'nul-niveau' - een veroordeling van de fetish kan daarom alleen geschieden vanuit een standpunt dat niet van deze wereld is.

8) Ik gebruikte deze handzame metafoor reeds eerder: zie mijn Narrative logic. A semantic analysis of the historian's language. Den Haag 1983: 135, 136.

9) M. Foucault, Nietzsche, genealogy, history, in: id., Language, counter-memory, practice, Ithaca 1986; 146.

10) H. White, The politics of historical representation in: id., The content of the form, Baltimore 1987; 73.

11) Foucault, op. cit., 147.

12) C. Taylor, Foucault on freedom and truth, in: id., Philosophical papers 2., Philosophy and the human sciences, Cambridge 1985.

13) Zie bijvoorbeeld de inleiding tot de esthetica: A. Sheppard, Aesthetics. An introduction to the philosophy of art, Oxford 1987; daanuit de hoofdstukken 2, 3 en 4.

14) N. Goodman, Languages of art, Indianapolis 1978; 53.

15) Voor de problematiek van 'tonen' versus 'beschrijven' zie S. Bann, The clothing of Clio, Cambridge 1984; hfdstk. 1 en voor de voorgeschiedenis van deze voor de geschiedbeoefening zeer wezenlijke oppositie C. Ginzburg, Ekphrasis and quotation, in: Tijdschrift voor Filosofie 50 (1988); 3-20.

16) Goodman, op. cit., 233.

17) $\mathbf{I k}$ betoog dit in mijn Twee vormen van narrativisme, in: Tijdschrift voor Filosfie 50 (1988); 40-81. 